contains a workroom, kitchen, verandah, and dormitory accommodation, etc. The site is about half an hour's walk from the Narrabeen tram terminus, and is within easy reach of French's Forest, Kuring-gai Chase, Deep Creek and Long Reef. It provides therefore an excellent centre for the study in their native habitats of the fauna and flora of sandstone scrub, forest, palm groves, fresh-water swamps, lagoons and beaches. The neighbourhood is also a sanctuary for native birds The research work to be done at this station, which is the first of its kind to be founded in Australia, will range from simple individual work to extended studies by teams of observers, in which botanists, zoologists and geologists may all take part. Among interesting researches which stand to the credit of senior members of the Society are Prof. W. J. Dakin's work on the food and breeding habits of the fish in Australian coastal waters, and Prof. T. G. B. Osborn's researches on Australian native fodder plants and grasses. The new station will also allow biological students to carry out under ideal conditions the field work which forms part of their training.

\section{Early Plant Hybridisation}

Further records of plant hybridisation before Kölreuter are given by Dr. C. Zirkle $(J$. Heredity, 25, No. 1), his earlier studies of this subject having been reviewed in NATURE of March 18, 1933, p. 393. Many early writers noted different coloured grains on the same ear of maize, the earliest recorded being by Tabernaemontanus (1588). Cotton Mather, in a letter to James Petiver in 1716, which is preserved in the Sir Hans Sloane collection of the British Museum, described natural crossing between different colour varieties of maize. This letter is published in full. Crossing in Cucurbita was also described. Thomas Fairchild is generally credited with having produced the first artificial plant hybrid, about 1716 . From records of Richard Bradley and the minutes of the Royal Society it is concluded that the hybrid first appeared spontaneously, and was then produced by crossing a carnation as female with the pollen of a Sweet William. Bradley himself recorded Auricula hybrids in 1717 and commented on the effect of foreign pollen in several varieties of apples and melons. Other English hybridisers of the same period are Thomas Knowlton, whose observations on Dianthus species hybrids were reported to the Royal Society in 1720; Thomas Henchman, Prebendary of Salisbury, who in 1729 noted the crossing of pea varieties and the occurrence of blue and white seeds in the same pod; and Benjamin Cooke, who in the Isle of Wight described crossing between maize varieties in 1749 (Phil. Trans. Roy. Soc., vol. 46). Twelve different investigators have now been found who described plant hybridisation before Kölreuter.

\section{Spread of the Water Hyacinth}

IN tropical waters, the water hyacinth, Eichhornia crassipes, Solms., a native of South America, a freely floating or loosely attached water plant supported by its curious buoyant bladder-like petioles, very readily becomes a serious pest, blocking waterways to navigation and converting fertile land near the waterways into stagnant swamps. F. P. Jepson, controller of plant pests, Department of Agriculture, Ceylon, has directed attention to the spread of this pest (Trop. Agric., 81, Dec. 1933). Introduced into Ceylon in 1905, probably as an ornamental plant, it has spread until in 1933 it ranges over some thousands of acres of water, paddy and swamp. At present, the infested areas lie within the inhabited zones, but Mr. Jepson contemplates with dismay the possible results of its finding its way to the vast uninhabited regions traversed by some of the larger rivers. Chemical methods of extinction are still being experimented with, but until now removal by hand has been most effective, the weed being then piled up and burnt. The chief difficulty in the control of the pest has been the apathy of the landowners and others responsible for the irrigation dams and water tanks. For this reason, Mr. Jepson's account is written in an educational and propagandist spirit, and makes clear the necessity for co-operation between private individual and Government if the water hyacinth is to be brought under control.

\section{"Marmite"}

THE yeast extract "Marmite" has long been recognised as a source of the vitamin $\mathrm{B}$ complex; more recently it has been found of value in various types of anæmia. Marmite has been compared directly with the international standard vitamin $\mathbf{B}_{1}$ preparation and found to contain 840 international units per oz., so that it is a potent source of this vitamin. It contains also vitamin $\mathrm{B}_{2}$ and other substances extractable from yeast, among which may be mentioned the 'extrinsic' factor required for normal blood formation. It is now generally considered that normal hæmatopoiesis depends upon the interaction of an 'intrinsic' factor present in the juice secreted by a healthy human stomach and an extrinsic factor present in the food : the compound formed by the interaction of these two factors is stored in the liver. In true pernicious anæmia, there is a deficiency in the secretion of the intrinsic factor, so that cure can only occur when the complete hæmatopoietic factor is supplied, as by giving liver or a preparation of it. In other anæmias, such as tropical macrocytic anæmia, it appears that the intake of the extrinsic factor is deficient ; cure can then be brought about by administering marmite. The effectiveness of marmite in anæmia is not due apparently to any constituent of the vitamin B complex present in the extract. Marmite is supplied by the Marmite Food Extract Co., Ltd., London, E.C.3.

\section{Fog Peril to Fishermen Lessened}

The United States fishermen who use dories (small flat-bottomed boats) to fish on the Grand Banks run a serious risk of drifting out to sea in a fog. This danger can now be very successfully overcome by the use of small radio transmitting sets weighing $20 \mathrm{lb}$. which can signal the position of the scattered 